\title{
Characteristics of deep penetration laser welding of dissimilar metal Ni-based cast superalloy K418 and alloy steel 42CrMo
}

\author{
Xiu-Bo Liu ${ }^{\mathrm{a}, \mathrm{b}}$, Ming Pang ${ }^{\mathrm{a}}$, Zhen-Guo Zhang ${ }^{\mathrm{b}}$, Wei-Jian Ning ${ }^{\mathrm{a}}$, Cai-Yun Zheng ${ }^{\mathrm{a}}$, Gang Yu ${ }^{\mathrm{a}, *}$ \\ ${ }^{\mathrm{a}}$ State Key Laboratory of Nonlinear Mechanics, Institute of Mechanics, Chinese Academy of Sciences, 15 Beisihuanxi Road, Beijing 100080, PR China \\ ${ }^{\mathrm{b}}$ School of Materials \& Chemical Engineering, Zhongyuan Institute of Technology, 41 Zhongyuan Western Road, \\ Zhengzhou 450007, Henan Province, PR China
}

Received 30 November 2006; accepted 29 March 2007

Available online 16 May 2007

\begin{abstract}
Experimental trials of autogenous deep penetration welding between dissimilar cast Ni-based superalloy K418 and alloy steel $42 \mathrm{CrMo}$ flat plates with $5.0 \mathrm{~mm}$ thickness were conducted using a $3 \mathrm{~kW}$ continuous wave $(\mathrm{CW}) \mathrm{Nd}$ :YAG laser. The influences of laser output power, welding velocity and defocusing distance on the morphology, welding depth and width as well as quality of the welded seam were investigated. Results show that full keyhole welding is not formed on both $\mathrm{K} 418$ and $42 \mathrm{CrMo}$ side, simultaneously, due to the relatively low output power. Partial fusion is observed on the welded seam near 42CrMo side because of the large disparity of thermal-physical and high-temperature mechanical properties of these two materials. The microhardness of the laser-welded joint was also examined and analyzed. It is suggested that applying negative defocusing in the range of Raylei length can increase the welding depth and improve the coupling efficiency of the laser materials interaction.
\end{abstract}

(C) 2007 Elsevier Ltd. All rights reserved.

Keywords: Laser processing; Metals and alloys; Welded seam

\section{Introduction}

Turbocompressor rotor, a core component of turbocompressor, is usually manufactured in China by welding the Chinese cast Ni-based superalloy K418 turbo disk to the quench-tempered Chinese 42CrMo alloy steel shaft. The thermal-physical and high-temperature mechanical properties of the above two materials are so different (see Tables 1 and 2) and, the Ni-based superalloy possesses great susceptibility to cracking in the heat-affected zone (HAZ) during welding. Moreover, the carbon equivalent of the medium carbon steel $42 \mathrm{CrMo}$ is about $0.834 \%$, which means it possesses strong quenching harden tendency and the welding ability is rather poor. Therefore, this welding process belongs to the typically dissimilar materials welding and is usually considered to be a great challenge. At present, the welding methods of these two materials are either electronic-beam welding or friction welding. How-

\footnotetext{
*Corresponding author. Tel.: + 86106252 1859; fax: +86106252 1859

E-mail address: gyu@imech.ac.cn (G. Yu).
}

ever, the electronic-beam welding process needs vacuum chamber and produces harmful X-rays. On the other hand, building a large vacuum chamber to contain very huge component in order to carry on the electronic beam welding is not practicable. As for the friction welding, low stress destruction often occurred and welding defects are usually observed near the fusion zone and results in lower production efficiency. For a long time, failures of such joints have plagued Chinese turbocompressor makers [1-4].

Laser welding is a high-energy-density, low heat-input process with specific advantages over conventional fusionwelding processes. These include high welding speed, narrow HAZ, low distortion, ease of automation, singlepass thick section capability and enhanced design flexibility. One of the many features of laser welding is the capability to weld without filler materials (autogenous welding) and it offers distinct advantages [5-9]. Laser welding has recently received growing attention due to its special features and potential. In terms of weldability for metallic materials, Nd:YAG laser has various advantages, such as a high-energy absorption rate due to a low 
Table 1

Thermal-physical properties of $42 \mathrm{CrMo}$

\begin{tabular}{|c|c|c|c|c|c|c|c|c|c|c|c|c|}
\hline & \multicolumn{12}{|c|}{ Temperature $(\mathrm{K})$} \\
\hline & 293 & 373 & 473 & 573 & 673 & 773 & 873 & 973 & 1035 & 1073 & 1173 & 1273 \\
\hline Specific heat, $C_{\mathrm{p}}(\mathrm{J} /(\mathrm{kg} \mathrm{K}))$ & 470 & 484 & 521 & 560 & 607 & 668 & 745 & 873 & 1075 & 796 & 684 & 677 \\
\hline Coefficient of thermal conductivity, $K(\mathrm{~W} /(\mathrm{mK}))$ & 39 & 36 & 35 & 34 & 33 & 31 & 29 & 25 & 20 & 21 & 24 & 23 \\
\hline
\end{tabular}

Table 2

Thermal-physical properties of K418

\begin{tabular}{|c|c|c|c|c|c|c|c|c|c|c|}
\hline Temperature/K & 293 & 373 & 473 & 573 & 673 & 773 & 873 & 973 & 1073 & 1173 \\
\hline $\mathrm{C}_{\mathrm{p}} /(\mathrm{J} /(\mathrm{kg} \cdot \mathrm{K}))$ Specific heat & 529 & 535 & 549 & 573 & 542 & 565 & 602 & 650 & 706 & 763 \\
\hline $\mathrm{K} /(\mathrm{W} /(\mathrm{m} \cdot \mathrm{K}))$ Coefficient of thermal conductivity & 9 & 10 & 12 & 13 & 14 & 16 & 18 & 21 & 24 & 28 \\
\hline
\end{tabular}

Table 3

Chemical composition of K418 (wt\%)

\begin{tabular}{|c|c|c|c|c|c|c|c|c|c|c|c|c|c|c|c|}
\hline $\mathrm{C}$ & $\mathrm{Cr}$ & Mo & $\mathrm{Nb}$ & $\mathrm{Al}$ & $\mathrm{Ti}$ & $\mathrm{Zr}$ & B & $\mathrm{Mn}$ & $\mathrm{Si}$ & $\mathrm{P}$ & $\mathrm{S}$ & $\mathrm{Fe}$ & $\mathrm{Pb}$ & $\mathrm{Bi}$ & $\mathrm{Ni}$ \\
\hline $.08-0.16$ & $11.5-13.5$ & $3.8-4.8$ & $1.8-2.5$ & $5.5-6.4$ & $0.5-1.0$ & $0.06-0.15$ & $0.008-0.020$ & $\leqslant 0.50$ & $\leqslant 0.50$ & $\leqslant 0.015$ & $\leqslant 0.010$ & $\leqslant 1.0$ & $\leqslant 0.001$ & $\leqslant 0.0001$ & Bal \\
\hline
\end{tabular}

reflectivity, a high welding speed, and a low residual stress compared to $\mathrm{CO}_{2}$ laser. Therefore, the application of $\mathrm{Nd}$ :YAG laser to weld metallic materials is steadily being increased. It has been widely implemented in industrial applications, e.g. in the automotive industry [10,11]. However, presently laser power levels are still limited for the material thickness involved. Recently, we have successfully made the full penetration butt-welding joints between K418 and 42CrMo flat plates with the same thickness of $3.5 \mathrm{~mm}$ by appropriate selection of processing parameters [12]. In this paper, $5.0 \mathrm{~mm}$ thickness $\mathrm{K} 418$ and 42CrMo flat plates have been tested for butt welding by Nd:YAG laser. The aim of this experimental work is to explore the possibility of welding of the above two materials with more thickness by laser and enlarge the application scope of laser-welding technology, especially in the area of thicker metallic materials, as well as the materials that is difficult to weld by conventional welding methods.

\section{Experimental details}

K418 Ni-based cast superalloy and the quench-tempered $42 \mathrm{CrMo}$ steel plates, with the thickness of $5.0 \mathrm{~mm}$, were put edge to edge. Tables 3 and 4 show the detail chemical compositions of these two materials. Before welding, any oxide layers and contamination were removed from the surfaces of the plates, especially the surfaces for welding were cleaned with acetone, ethanol and then dried. The accuracy requirement for the platform is very high during laser-welding process, the horizontal and vertical accuracies were adjusted through the micrometer and the error range was within $\pm 0.04 \mathrm{~mm}$. Flow of high-purity argon gas was passed through the molten pool from both top and
Table 4

Chemical composition of $42 \mathrm{CrMo}(\mathrm{wt} \%)$

\begin{tabular}{llllllll}
\hline $\mathrm{C}$ & $\mathrm{Cr}$ & $\mathrm{Mo}$ & $\mathrm{Mn}$ & $\mathrm{Si}$ & $\mathrm{P}$ & $\mathrm{S}$ & $\mathrm{Fe}$ \\
\hline
\end{tabular}

$0.38-0.450 .90-1.200 .15-0.250 .50-0.800 .20-0.40 \leqslant 0.040 \leqslant 0.040$ Bal

lateral sides to provide a protective environment for the sake of avoiding the possible reaction between the molten metals and ambient air.

Experiments of laser welding of the above two materials were carried out on a $3 \mathrm{~kW}$ continuous wave $(\mathrm{CW})$ $\mathrm{Nd}$ :YAG laser materials processing systems with numerical control, which carries out the spatial displacement of the assembly without any filler metal. An oblique irradiation technique was employed to overcome the problems of dissimilar materials in certain extent. The employed parameters were determined and optimized based on adequate number of the preliminary trials for the laser welding of these two materials plate with the thickness of $3.5 \mathrm{~mm}$ [12], i.e., laser output power varied between 2.5 and $3 \mathrm{~kW}$, laser beam scanning velocity varied between 15 and $20 \mathrm{~mm} / \mathrm{s}$, direction of the side-blow shielding gas was determined to opposite to the welding direction, with a angle of $35^{\circ}$ to the horizon plane and the gas flow rate of $151 / \mathrm{min}$ based on adequate number of the preliminary trials [12], as well as the defocus distance spanned from -3 to $+1 \mathrm{~mm}$. The definition of defocus distance is positive when the focus point is above and negative when the focus point is beneath the surface of the work-piece. The aim of this design was to investigate the influences of each parameter on the weld quality when other parameters were kept constant and acquire the optimized parameters 
window for high-quality full penetration welded joint. The whole laser-welding system was illustrated in Fig. 1. After welding, no post-weld heat treatments were performed.

The microhardness along the transverse direction of the welded joint was measured by an automatic microhardness tester (HXD-1000B, Shanghai Optics Apparatus Ltd., China) with a testing load of $1.96 \mathrm{~N}$ and a dwelling time of $15 \mathrm{~s}$. The average values of hardness were determined by at least five points of measurements.

\section{Results and discussions}

\subsection{Morphology of the welded seam}

The power density available from a laser beam spans many orders of magnitude and can attain approximately $10^{8} \mathrm{~W} / \mathrm{cm}^{2}$. A power density below approximately $10^{6} \mathrm{~W} /$ $\mathrm{cm}^{2}$ allows welding to be performed in the thermalconductive mode. The beam energy is deposited on the material surface, transferred into the material by conduction, and a hemispherical weld bead is formed in a similar manner to conventional fusion-welding processes. In

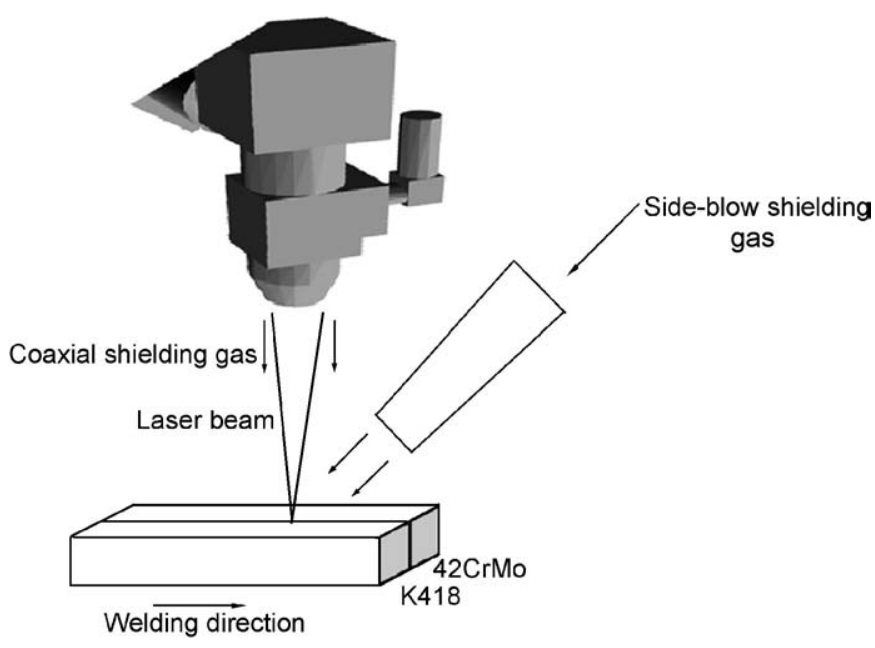

Fig. 1. Schematic diagram of the experimental setup.

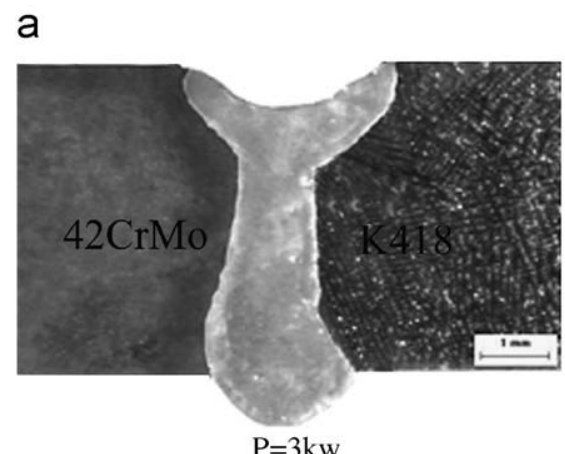

b

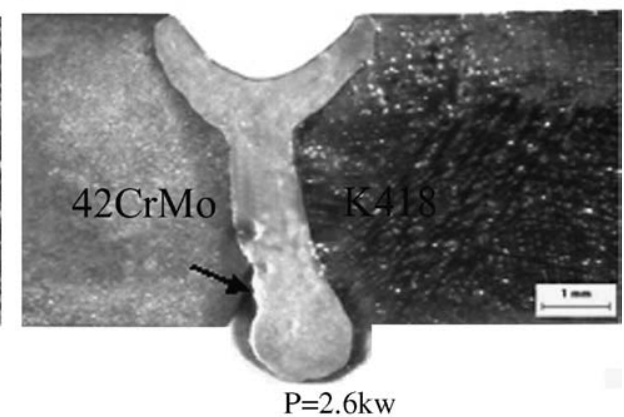

Fig. 2. Cross-section morphologies of welded seam of K418 and $42 \mathrm{CrMo}$. Fixed welding parameters: welding velocity $15 \mathrm{~mm} / \mathrm{s}$ and defocus distance $-1 \mathrm{~mm}$. 


\subsection{Influence of laser output power}

Fig. 3 shows that both the welding depth and width increased with the increasing of the output power of laser. This is because a higher output power is naturally expected to increase the linear energy imposed on the welded seam, hence causing a comparatively large amount of melted or vaporized metal. However, because the increased laser energy is mainly consumed by the increased welding depth through keyhole effects, the welding width was not so sensitive to the laser output power and only slightly increased. Our results were in reasonable agreement with other researchers' work [13] in this respect, who also demonstrated that the laser output power had more pronounced influence on the welding depth than that of welding width. By observing the cross-section of the welded seam, it is clear that full penetration welding occurred in the K418 side, while partial fusion occurred in the $42 \mathrm{CrMo}$ side within the laser output power range of $2.5-2.9 \mathrm{~kW}$. While in the range of $2.6-3.0 \mathrm{~kW}$, shallow concave shape existed in the facade and convex shape occurred in the rear side and the concave area is commensurate with the convex area, which implies that the concave in the facade side is caused by the collapse of the welded seam due to the synthetical effects of the surface tension and gravity of the molten pool itself.

\subsection{Influence of welding velocity}

Fig. 4 shows the welding depth and width variations under various laser scan speed. It is noted that the welding depth and width were decreased with the increase of the laser scan speed. Because the welding speed matches an opposite with the heat input, so the increasing of the welding speed means the decreasing of the linear energy per

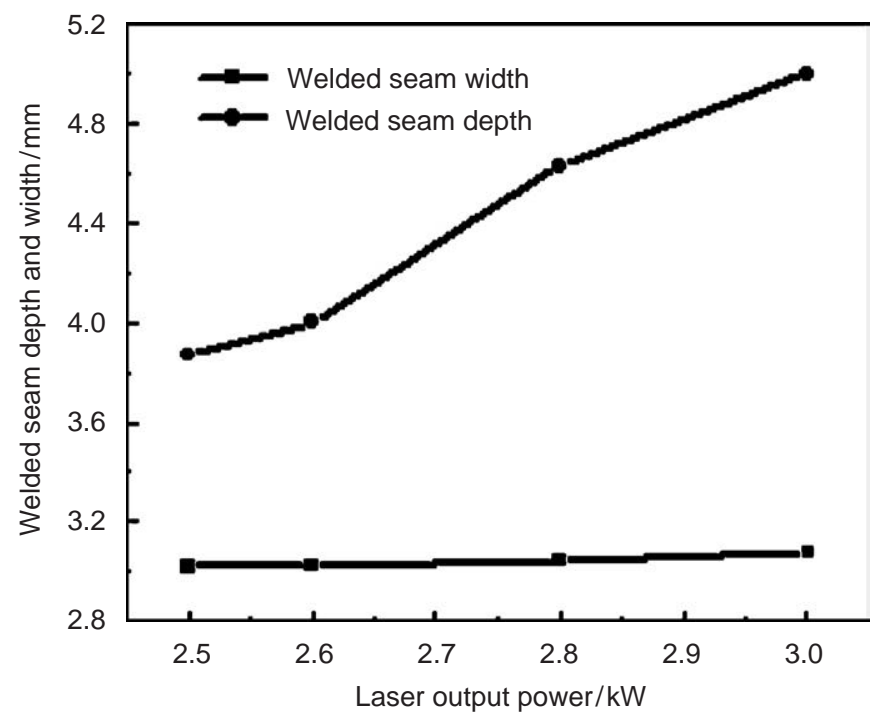

Fig. 3. Influence of laser power on welded seam depth and width. Fixed welding parameters: welding velocity $15 \mathrm{~mm} / \mathrm{s}$ and defocus distance $-1 \mathrm{~mm}$.

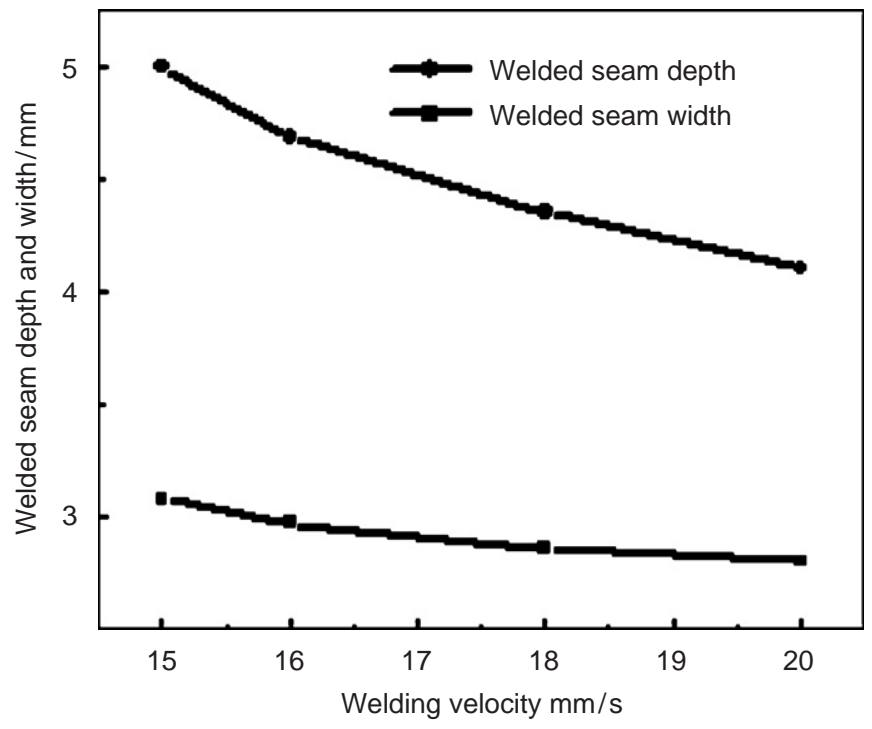

Fig. 4. Influence of welding velocity on welded seam depth and width. Fixed welding parameters: laser output power $3 \mathrm{~kW}$ and defocus distance $-1 \mathrm{~mm}$.

unit weld length exerted on the welding line, thereby producing a small amount of intermixed melt and finally a thinner welding depth and narrower width. Our results show that the influence was more pronounced on welding depth. This is different from that of Ref. [14], in that case, the welding velocity had more influence on welding width than welding depth during partial penetration $\mathrm{CO}_{2}$ laser welding. The reasons resulted in this dissimilarity are not very clear yet and now under further investigation. By observing the cross-section of the welded seam, a full penetration welding occurred near the K418 side within the speed range of $15-20 \mathrm{~mm} / \mathrm{s}$, while partial fusion occurred near the $42 \mathrm{CrMo}$ side in the range of $16-20 \mathrm{~mm} / \mathrm{s}$.

\subsection{Influence of defocus distance}

The power density exerted on the work-piece depends on both the laser beam's power density and the relative distance between the surface of the work-piece and the focus plane. We define the defocus distance as positive when the focus plane is up on the surface of the work-piece and negative when the focus plane is beneath. Of course, different defocus distance represents different power density that exerted on the work-piece by laser. As shown in Fig. 5, full penetration welding occurred under the defocus distance range of -2 to $0 \mathrm{~mm}$, while no full penetration welding occurred for -3 to $+1 \mathrm{~mm}$, and the welding width increased with the increasing of positive and negative defocus distance. It is known from the laser beam transfer characteristics that the laser spot is the smallest in the focus plane and the power density is the largest and the laser beam gradually diverged as away from the focus point. However, the laser beam fluctuates very little in the range of Raylei length. For the positive defocus distance, the laser beam enters the keyhole diverged gradually and 


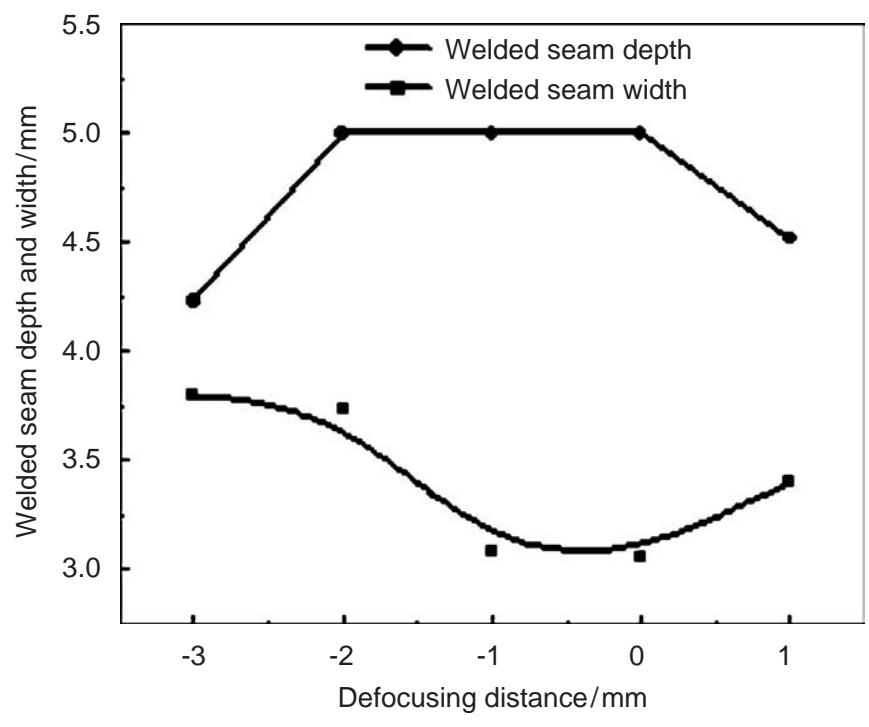

Fig. 5. Influence of defocusing distance on welded seam depth and width. Fixed welding parameters: laser output power $3 \mathrm{~kW}$ and welding velocity $15 \mathrm{~mm} / \mathrm{s}$.

induces decreased power density and the attendant decreased welding depth; while for the negative defocus distance, the laser beam enters the keyhole converged gradually to the focus point and imposes higher power density than that of the surface of the work-piece, favoring more strong melting and vaporization, facilitating the transfer of the laser energy to more depth, and thus deeper the welding depth. Nevertheless, if the negative defocus distance surpasses the laser Raylei length greatly, the dimension of the laser spot increases sharply, changing the space distribution of the laser power density, thus decreasing the welding depth. The welding width increases with the increasing of defocus distance, this is because with the increasing of positive and negative defocus distance, the spot area irradiated on the facade side of the welding seam is increased, inducing the increasing of melted metal. By observing the welded seam cross-section, concave or collapse occurred within the defocus range of -3 to $+1 \mathrm{~mm}$.

\subsection{The microhardness tests}

The hardness of material represents its capability to resist the occurrence of local plastic deformation under load. It is considered that most of the mechanical properties are related to the hardness of the material. Table 5 shows the microhardness test results of the laser-welded joint. It could be seen that the microhardness of the welded seam was the lowest and, averaged at about HV220.46. While the microhardness of the HAZ of the K418 was about 428.01 , and then, quickly changed to the base metal, i.e., about HV 395.10. The microhardness of the HAZ of the 42CrMo was the highest, ranged between HV646 and HV689 and then gradually transferred to the base metal, about HV409.42.
Table 5

Microhardness of the laser-welded joint (HV)

\begin{tabular}{lllllll}
\hline & \multicolumn{2}{l}{ Region } & & & \multirow{2}{*}{ Average } \\
\cline { 2 - 6 } & 1 & 2 & 3 & 4 & 5 & \\
\hline Base K418 & 400.00 & 382.34 & 405.30 & 401.32 & 386.56 & 395.10 \\
HAZ of K418 & 426.54 & 424.02 & 449.49 & 424.74 & 415.25 & 428.01 \\
Welded seam & 213.53 & 225.84 & 213.53 & 227.93 & 221.45 & 220.46 \\
HAZ of 42CrMo & 646.62 & 695.11 & 680.98 & 674.48 & 689.07 & 667.85 \\
Base 42CrMo & 419.75 & 369.07 & 414.85 & 425.82 & 417.63 & 409.42 \\
\hline
\end{tabular}

The hardness of the welded seam was the lowest owing to the partial dissolution of the strengthening phase $\mathrm{Ni}_{3} \mathrm{Al}\left(\gamma^{\prime}\right)$ and, the subsequent rapid solidification inherent to laser processing could suppress the formation of the phase $\mathrm{Ni}_{3} \mathrm{Al}\left(\gamma^{\prime}\right)$ to some extent [15]. Also, the alloy elements coming from the $42 \mathrm{CrMo}$ could result some dilution effects of the molten pool. The reason why the hardness of the 42CrMo HAZ was the highest was ascribed to the self-quenching effects and the formation of a large amount of needle like martensite.

These results give useful indications for the development of an innovative laser-welding technique for the Ni-based cast superalloy K418 and alloy steel 42CrMo. Further work about the welding of these two materials with highquality and the practical components is strongly and urgently recommended, and this is currently underway in our laboratory in this respect.

\section{Conclusions}

Partial fusion was apt to occur near the 42CrMo side during the $\mathrm{CW} \mathrm{Nd}$ :YAG laser welding of dissimilar Nibased K418 superalloy and $42 \mathrm{CrMo}$ steel. Due to the insufficient rated laser output power, full penetration keyhole welding cannot be formed on both the K418 and $42 \mathrm{CrMo}$ sides during the welding of these two dissimilar materials with $5.0 \mathrm{~cm}$ thickness. In laser deep penetration welding, when the defocus distance is in the range of Raylei length, as the laser beam enters, the keyhole gradually diverges and the laser power density fluctuates very little in the range of Raylei length, thus increasing the utility ratio of the laser energy and the welded seam depth.

\section{Acknowledgments}

The authors are grateful for the financial support from the China Postdoctoral Science Foundation (Grant no. 20060400105). The invaluable assistance of Dr. Hong-Wei Song, engineer Li-Xin Wang of the Laboratory for Laser Intelligent Manufacturing, Institute of Mechanics, Chinese Academy of Sciences, during the laser welding experiments, was gratefully acknowledged. 


\section{References}

[1] Suigeng D, Li F, Jinwei W, Cao Y. Forming mechanism of carbide band in friction welding joint of superalloy K418 and steel 42CrMo. Chin J Nonferr Met 2003;13(2):323-7.

[2] Suigeng D, Li F, Cao Y, Jinwei W. On strengthening the friction welding joint between K418 Turbo disk and 42CrMo shaft. J North Polytech Univ 2004;22(1):112-5.

[3] Minlin Z, Hongqing S, Wenjin L, Xiaofeng Z, Jinjiang H. Boundary liquation and interface cracking characterization in laser deposition of Inconel 738 on directional solidified Ni-based superalloy. Scr Mater 2005;53:159-64.

[4] Yao XF, Yeh HY, Xu W. Dynamic initiation and propagation behavior of sub-interfacial cracks in PMMA/Aluminium biomaterial system. Fatigue Fract Eng Mater 2005;28(12):1191-8.

[5] Sun Z, Ion JC. Review, laser welding of dissimilar metal combinations. J Mater Sci 1995;30:4205-14.

[6] Sun Z, Kuo M. Bridging the joint gap with wire feed laser welding. J Mater Process Technol 1999;87:213-22.

[7] Wang HM, Chen YL, Yu LG. 'In-Situ' weld-alloying/laser beam welding of SiCp/6061 Al MMC. Mater Sci Eng A 2000;293:1-6.

[8] Sanderson A, Punshon CS, Russell JD. Advanced welding processes for fusion reactor fabrication. Fusion Eng Des 2000;49-50:77-87.
[9] Mai TA, Spowage AC. Characterization of dissimilar joints in laser welding of steel-koval, copper-steel and copper-aluminium. Mater Sci Eng A 2004;374:224-33.

[10] Ribolla A, Damoulis GL, Batalha GF. The use of Nd:YAG laser weld for large scale volume assembly of automotive body in white. J Mater Process Technol 2005;164-165:1120-7.

[11] Kuo TY, Lin HC. Effects of pulse level of Nd:YAG laser on tensile properties and formability of laser weldments in automotive aluminium alloys. Mater Sci Eng A 2006;416:281-9.

[12] Pang M, Yu G, Liu Z, Caiyun Z, Lixin W, Weijian N. Dissimilar metal of $\mathrm{K} 418$ and $42 \mathrm{CrMo}$ full penetration laser welding. Chin J Lasers 2006;33(8):1122-6.

[13] Youngtae Y, Donggyu A, Kungbo R, Seongwook S, Hojun S, Kiegon IM. Welding characteristics of S45C medium carbon steel in laser welding process using a high power CW Nd:YAG laser. J Mater Sci Lett 2004;39:6117-9.

[14] Chunming W, Lunji H, Xiyuan H. The relationship between plasma optic signal and penetration depth during partial-penetration laser welding. Laser Technol 2006;30(1):23-6.

[15] Ojo OA, Chaturvedi MC. On the role of liquated $\gamma^{\prime}$ precipitates in welded heat affected zone microfissuring of a nickel-based superalloy. Mater Sci Eng A 2005;403:77-86. 